\title{
Navigating (and Disrupting) the Digital Divide: Urban Teachers' Perspectives on Secondary Mathematics Instruction During COVID-19
}

\author{
Alesia Mickle Moldavan ${ }^{1}$ D $\cdot$ Robert M. Capraro ${ }^{2} \cdot$ Mary Margaret Capraro $^{2}$
}

Accepted: 3 July 2021 / Published online: 13 July 2021

(c) This is a U.S. government work and not under copyright protection in the U.S.; foreign copyright protection may apply 2021

\begin{abstract}
This study examines the perspectives and lived experiences of 10 urban secondary mathematics teachers from two epicenters of COVID-19 in the United States regarding their transition to digital learning during the 2019-2020 academic year. We use case study methodology with phenomenological interviews to gather insights into the teachers' efforts to modify their mathematics instruction and curriculum while navigating observed digital inequities and new digital tools for mathematics teaching. We also report on the teachers' targeted attempts to bridge home and school while problematizing the threatened humanistic aspect of remote teaching and learning. These frontline experiences recognize technology-associated systemic inequities in marginalized, urban communities and the need to strategize ways to implement equity-oriented technology integration that benefits all learners, especially urban youth. By critically examining digital education in the urban context, crucial conversations can transpire that critique (and disrupt) the digital divide in mathematics education and open doors for other stakeholders to broadly discuss the logistics and implications of digital education to enhance new ways of teaching and learning.
\end{abstract}

Keywords COVID-19 • Digital divide · Equity-oriented technology integration · Mathematics education · Urban education

Alesia Mickle Moldavan

amoldavan@fordham.edu

1 Graduate School of Education, Fordham University, 113 W. 60th St., New York, NY 10023, USA

2 Aggie STEM, Texas A\&M University, College Station, TX, USA 


\section{Introduction}

Change happens. Typically, it is glacial, slow yet continuous. Species face change every day, and how they respond determines if they adapt or disappear. Usually, cataclysmic rapid change annihilates species, and the observed sudden change can bring great danger and disruption. Teaching has experienced this cataclysmic change, moving from traditional, face-to-face instruction to a distanced model to which both teachers and students have had to quickly adapt. The ability to adapt is dependent on the scope of tools available in the face of change, and urban teachers, more so than anyone else in education, are facing this extinction juncture.

The COVID-19 pandemic called for an unprecedented response to re-envision mathematics instruction given the observed practical and pedagogical challenges facing urban teachers. The rapid transition to remote learning sought to mitigate the impact of missed in-person instruction (Reich et al., 2020) but placed urban mathematics teachers in a situation in which they had to consider innovative pedagogy to sustain effective learning while overcoming societal and digital inequities. Success in this transition was not guaranteed. Adoption of technology can both enhance inclusive instructional practices (Edyburn, 2013; Howland et al., 2011; Thomas \& Hong, 2013) as well as exacerbate issues of equity (Ferlazzo, 2020; Tichavakunda \& Tierney, 2018; Young \& Noonoo, 2020). Mathematics education, and the field at large, must examine the impact of digital privilege on marginalized and vulnerable students to be responsive to change and problematize solutions that empower urban teachers and students.

In recent years, a growing body of research has examined access to technology and the knowledge to use such technology by teachers and students for instructional purposes. Several related works (see Dolan, 2016; Fulton \& Sibley, 2003; Gorski, 2005; Puigjaner, 2016) criticize the societal impacts of a digital divide - the gap in access to digital resources and the knowledge to use resources to support learning - and suggest advocacy initiatives to reduce such gaps by prioritizing digital equity. Similarly, there have been recent technology-supported educational reform efforts in mathematics education (see Association of Mathematics Teacher Educators [AMTE], 2017; National Council of Teachers of Mathematics [NCTM], 2000, 2014a, 2014b) that acknowledge the need for digital resource considerations with access and equity at the forefront. Furthermore, there is need to research digital equity in terms of both the physical access to material (e.g., computer hardware, software, connectivity) and the social access of such resources that empower students to participate in learning (Gorski, 2009; Mäkinen, 2006).

Despite calls for digital equity advocacy, attempts to implement equity solutions in real-world settings are often met with limited success. Schools wishing to integrate technology-supported activities are responsible for securing digital resources appropriate for curricular goals as well as acquiring teacher training necessary for implementation. Making such a vision come to fruition requires significant resources and teacher support that has often proved challenging to secure but is of critical importance for mathematical success and excellence in 
urban spaces (Canhmann \& Remillard, 2002; Martin \& Larnell, 2013; Matthews, 2008; Tate, 2008; Walker, 2012). Because of this, the use of technology-assisted learning has been on a small scale, limiting the scope of equity-based research. However, the large-scale implementation of digital learning that followed in the wake of the COVID-19 pandemic has provided the opportunity for mathematics education researchers to more deeply analyze and reflect on the successes, limitations, and obstacles of digital learning technology equity than was previously possible.

In this study, we use case study methodology with phenomenological interviews (Seidman, 2013; Yin, 2014) to examine the perspectives and lived experiences of 10 urban secondary mathematics teachers from two epicenters of COVID-19 in the United States regarding their transition to digital learning during the 2019-2020 academic year. Specifically, we contextualize our study in New York City and Houston, Texas to focus on the stories of teachers who educate underrepresented racially minoritized students. To guide our inquiry, the following research question is examined: What are urban secondary mathematics teachers' perspectives and lived experiences transitioning to digital learning during the COVID-19 pandemic? The impetus for this study is to report on frontline experiences that provide insight into teachers' efforts to modify their mathematics instruction and curriculum while navigating observed digital inequities and new digital tools for mathematics teaching. Furthermore, these experiences recognize technology-associated systemic inequities in marginalized, urban communities and the need to strategize ways to implement equity-oriented technology integration that benefits all learners, especially urban youth. By critically examining digital education in the urban context, crucial conversations can transpire that critique (and disrupt) the digital divide in mathematics education and open doors for other stakeholders to broadly discuss the logistics and implications of digital education to enhance new ways of teaching and learning.

\section{Value of Free Education (with Technology) in America}

Historically, the promise of a free, high-quality $\mathrm{K}-12$ education originated with the states and, eventually, resulted in a federal law, which made it the law of the land. The movement started around 1790 when Pennsylvania became the first state to require a free primary education for even those who could not afford it. Soon after, New York passed similar legislation in 1805, but Massachusetts emerged as a leader in free public education with the creation of the first tuition-free high school in 1820 . In the 1830 s and 1840 s, the United States saw greater interest in public education, which was synonymous with a free, high-quality education.

During this time period, $\mathrm{K}-12$ schools in Ohio, as in much of the United States, operated independently with little interest in developing universal standards or teacher qualifications. The "Akron School Law of 1847" changed this independent practice by unifying the operations, curriculum, and funding of local school systems. Perhaps the most important contribution of the law was the provision that property taxes would pay for new schools and new school systems. 
Despite the growing strength of and support for public schooling laws, their passing was anything but a promise for a free, high-quality education for all (Jiménez et al., 2007). In fact, the Akron School Law excluded Black children from the public school system. It was not until 1930 that all 48 states (at the time) had passed laws making a free education compulsory for all students. President Johnson's signing of the Elementary and Secondary Education Act of 1965, which granted a large federal expenditure to each state for the purpose of sustaining local $\mathrm{K}-12$ systems (Paul, 2016), essentially enacted K-12 education for all as the law of the land. However, systematic racism, rather than legal segregation, stymied the promise of a free, highquality education for all. Black students were still educated in separate schools that were underfunded and under-resourced with teachers who were poorly supported.

Today, we have several federal and state legislative acts and consent decrees that were designed to deliver the promise of a free, high-quality education for all. For example, parents have the right to move their children from a low-performing school into a school where there is a higher quality of education, teachers, resources, and curriculum (Schneider et al., 2000). However, all too often these opportunistic changes fail miserably for minoritized and under-privileged students when participating in these programs (Renzulli, 2006). Is it possible that other factors can be a major contributor to a subtle, less obvious yet unjust problem of systematized discrimination?

We have seen during the COVID-19 pandemic how such largely unseen factors may contribute to and exacerbate systematized discrimination in education. Catastrophic events can precipitate a cascade of negative consequences that unequally distribute educational discrimination (Chen \& Peng, 2020). Furthermore, technology and internet access can now be viewed as a major contributor to children's learning (Gottschalk, 2019). In fact, a lack of such access can create educational inequities that impact academic achievement (Kuhfeld et al., 2020), especially for students living in urban contexts that can be disproportionately discriminated against in the public schooling arena. We see the compounding effects of such educational inequities with the traumatic consequences of the ongoing COVID-19 pandemic on public education and the need for digital learning.

\section{A Pandemic Localized in Urban Epicenters of Inequities}

Without a doubt, the COVID-19 pandemic has unmasked the vast disparities in racial, economic, and educational opportunities that have disenfranchised urban communities that were already the epicenters of such inequities. The unequal impact of the health crisis spotlighted the exposed fault lines that were already threatening people of color and those without proper access to healthcare, shelter, food, and educational resources (Armitage \& Nellums, 2020; Van Lancker \& Parolin, 2020). With recognition that the already fragile state was precariously balanced, the additional stressors resulting from COVID-19 may have caused those fault lines to rupture. New unemployment issues from the lack of federal and state support have only exacerbated food and housing insecurities (Wan, 2020). Additionally, schooling has 
been moved into students' living spaces, and those spaces are often ill-equipped for sustaining a twenty-first century quality education.

Urban schools and the teachers and students who study and work in them have also had to navigate the digital divide that has limited essential access to education. Urban schools already experience pervasive challenges with budget constraints, limited supplies, and stringent limitations on technology (e.g., inadequate equipment, lack of training; Boutte, 2012; Buendía, 2011; Milner, 2010). Compound these hardships with the lower quality internet options often favored by budget-conscious consumers and those facing economic hardships, who are more likely to live in urban rather than nonurban school districts (Wachira \& Keengwe, 2011), and this is a recipe for disaster for urban youth. Reports from the American Community Survey indicate that $88 \%$ of 3- to 18 -year-olds have home internet access through a computer (e.g., laptop, tablet), while 6\% have access only through a smartphone and 6\% do not have internet access at all (National Center for Education Statistics [NCES], 2020). With approximately 56.6 million students enrolled in grades K-12 (NCES, 2020), roughly 6.8 million students either lack internet access or do not have a computer device at home. The percentage of students who lack internet access is higher for students living below the poverty threshold as well as students living in cities and remote rural areas in comparison to students in suburban areas (NCES, 2018). Learning that requires such access puts those with access at a participatory advantage in learning over their digitally disadvantaged counterparts, which in the longterm plays key roles in various outcomes ranging from academic performance to career success (Robinson et al., 2015). Recognizing that digital disparities can reinforce social inequities, there is a need to examine how such inequities perpetuate inabilities to competitively participate academically, a disadvantage that carries over into postsecondary opportunities and eventually constrains employment options.

Attention must also be placed on offering school-based technology training that bridges technology and learning techniques as well as sustains innovative digital pedagogy. Research on the various types of technologies (e.g., mobile, videos, calculators, digital libraries and learning objects, virtual learning environments) used in the mathematics classroom offers a glimpse into the ever-evolving trends and constant development of digital tools that redefine the ways in which we organize and access knowledge as well as socially interact in learning contexts (Borba et al., 2016). A research-based understanding of how such technology can impact mathematics learning can provide insight into how teachers and students capitalize on the associated learning potential of such digital tools. Further, considerations must also be made to use the technology to its fullest and align such initiatives within the context of technology-supported educational reform efforts (see AMTE, 2017; NCTM, 2000, 2014a, 2014b).

When access and knowledge to use technology is available, teachers and students can reap the benefits of technology. NCTM (2000, 2014b) addresses how appropriate technology in mathematics instruction can assist with visualizing mathematical ideas, organizing and analyzing data, and communicating mathematical reasoning and problem solving. Furthermore, research has shown that using digital tools can provide students with access to resources that aid in conceptualizing mathematical ideas (Mickle \& Junor Clarke, 2015; Thomas \& Hong, 2013). Thus, it is imperative 
mathematics teachers advocate for technology integration in mathematics instruction. To properly advocate and provide effective recommendations, the field must learn from the observed practical and pedagogical challenges and opportunities of digital education.

\section{Digital Empowerment to Enhance Learner Participation in Mathematics}

Digital education can offer learners opportunities to receive information that they may not have access to otherwise. While there can be pitfalls to accessing technology (Kreijns et al., 2003), learners who have access benefit from new forms of interaction and multidimensional communication, even if the technology itself may not be interactive (Mäkinen, 2006). Furthermore, technology can be used to build new skills, share information, and connect social networks. This final aspect allows technology to enrich participation by creating digital bridges to marginalized learners or remote areas, thereby arranging opportunities to enhance involvement and empower learners to be included and active in mathematics learning. However, developing social mathematics awareness in a digital environment may throttle participation when transitioning from in-person learning because of the new environment, unfamiliar peer interactions, and any difficulties resident in the technological space. These difficulties can be overcome, however. As learners adapt to their new digital environment and improve their technical skills, they can develop competencies in technology use and increase their confidence to strategically use technology to develop their learning skills and social mathematics awareness, explore personal interests, and pursue self-driven learning trajectories (Mäkinen, 2006).

In recent decades, technology has opened pathways for learners to engage with mathematics content in authentic contexts as well as foster learner agency and autonomy (Olive et al., 2010). Technology use has also altered aspects of collaboration and mathematical exploration in terms of problem solving and inquiry (Geiger et al., 2010). Computer-assisted instruction coupled with calculators, dynamic software, simulators, visualizers, and other real-time manipulation features have offered mathematics instruction efficiency tools that increase computational speed and accuracy while assisting learners in developing conceptual knowledge of mathematics (Sinclair et al., 2010). In addition to technology, advances in pedagogical strategies that integrate technology through technology-enhanced learning activities have positioned the teacher as a facilitator of learning with emphasis placed on learner exploration, inquiry, and collaboration (Bray \& Tangney, 2017). In this manner, technology serves as a tool to provide learners new ways of constructing and visualizing problems that in turn support the development of higher-order thinking skills (Cradler et al., 2002) and motivate students to take on more of their own mathematics learning (Carpenter et al., 2015). The perceived potential of technologyenhanced learning activities emphasizes the need for sustainable teacher support as well as advocacy for its use in the classroom to enhance the mathematics learning experience. 
A further look into technology use in the context of urban mathematics education can be particularly helpful in illuminating how technology use is perceived by teachers in the classroom. Several external and internal barriers are often identified by urban mathematics teachers that hinder their technology integration (Wachira \& Keengwe, 2011). Per the external barriers, teachers frequently note availability issues when obtaining technology, obstacles with working with unreliable technology, and lack of technology support and leadership. As for the internal barriers, teachers repeatedly express concerns for lack of time to develop competencies in using such tools and the needed pedagogical knowledge to effectively integrate the technology into their instructional practices. Inadequate and unreliable technology as well as poor technical support can discourage teachers from developing interest and confidence in using technology, thereby impacting their dispositions toward technology use in the mathematics classroom. For digital education to enhance learner participation, conscious efforts must be made to make sure resources are available to teachers and learners.

\section{Theoretical Framings for Understanding}

To guide our inquiry, we considered an intersection of theoretical framings to gather an understanding of urban secondary mathematics teachers' perspectives and lived experiences transitioning to digital learning. Building on the various works of Vygotsky's (1978) sociocultural theory, Piaget's (1975/1985) sociocognitive conflict theory, and Bandura's (1986) social cognitive theory, we referenced a social constructivist framework to acknowledge that teachers construct meaning and knowledge through their participation in the field (Ertmer \& Newby, 2013; Kalpana, 2014). Maintaining the perception that learning occurs through social and cultural encounters enabled us to view teachers' knowledge as multiple realities of experiential-constructions that are socially affirmed through their engaged practices. The active role teachers take in transitioning their instructional practices into digital environments often requires paradigm shifts in content delivery, learning modalities, and assessment to elicit student engagement and mathematical understanding. The type of social constructivism that teachers use to make sense of their perspectives is reflective of the basic principle that "learning is not a passive receiving of readymade knowledge but a process of construction... [where the teachers] themselves are the primary actors" (Anthony, 1996, p. 349). Thus, investigating the active selfreflection and personal learning that teachers engage in is crucial for understanding the transition to digital learning environments. This personal knowledge is critical for examining perspectives and informing what shared inputs may offer more broadly for education, pedagogy, and practice.

Theories of adult learning also provide insights into how teachers respond to learning through critical reflections of their assumptions (Johnson \& Olanoff, 2020). Transformative learning has been defined as an adult learning theory that alters the way people perceive themselves within the world around them and involves a "shift of consciousness" (Mezirow, 1991, 2012; Teaching Excellence in Adult Literacy, 2011). During COVID-19, teachers have had to alter their perceptions about what 
it means to be a teacher and the world in which they teach (Armitage \& Nellums, 2020). They have had to learn how to respond to the challenges of COVID-19 and navigate the impeding implications of social and digital inequities (Wan, 2020) as well as technology changes (e.g., remote learning, technology access and expertise). As a result, these interwoven factors have shifted teachers' frames of reference as they adapt their learning to the immediate context (Roessger, 2014), thereby transforming their thinking toward mathematics instruction. Figure 1 illustrates how these two theories have served to frame our epistemological underpinnings and communicate the changing landscape of teaching.

\section{Methodology}

Using a qualitative case study methodology, we conducted phenomenological interviews to gather insight into the perspectives and lived experiences of urban secondary mathematics teachers as they transitioned to digital learning during the onset of COVID-19. The holistic nature of a qualitative case study enables researchers to study human experiences and shared understandings within a particular context amongst important circumstances (Yin, 2014). Our context that defined the case included urban secondary mathematics teachers located in two epicenters of COVID-19 during the spring semester of the 2019-2020 academic year; therefore, the research is framed around the initial response to COVID-19 beginning around March 2020 through the remainder of the academic year.

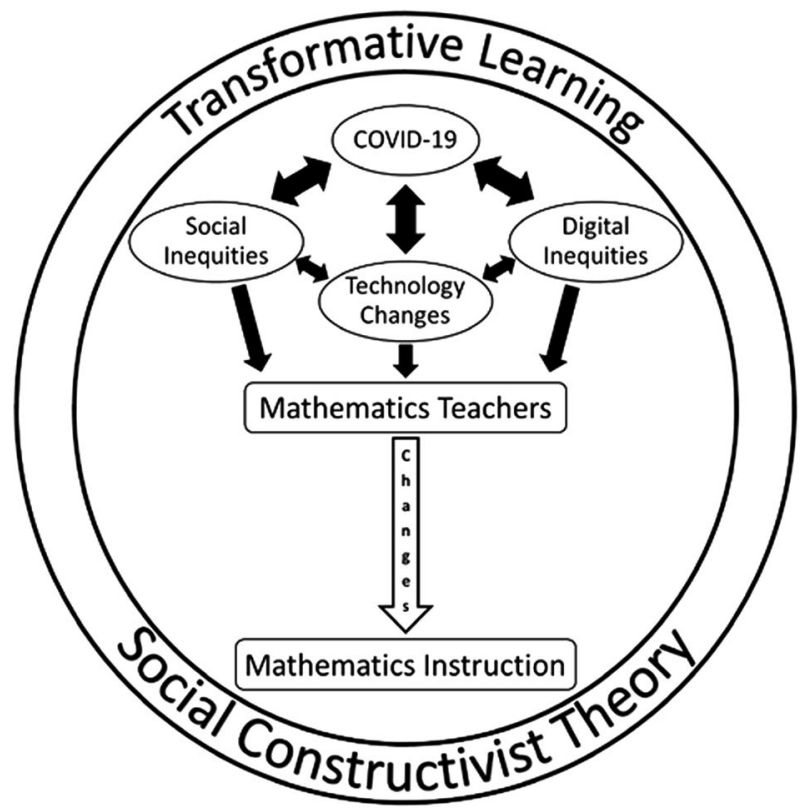

Fig. 1 Intersection of transformative learning and social constructivist theories 


\section{Context and Participants}

Acknowledging that "urban" is a socially constructed and disputed concept lacking a common definition (Buendía, 2011; Milner, 2012; Schaffer et al., 2018), we defined the study's urban context in reference to Welsh and Swain's (2020) six considerations for categorizing urban: geographical location, enrollment size, student demographic composition, school resources, educational inequalities, and social/ economic contexts. The participants included 10 urban secondary mathematics teachers from various schools in New York City and Houston, Texas (see Table 1). These cities were targeted for this study because they both had school districts close their doors in March 2020 and institute remote learning for the rest of the academic year. The urban context characterizing both cities also presented similar situations and prompted similar responses to COVID-19, and these influenced issues related to education, healthcare, and socioeconomic hardships in comparable ways. For recruitment purposes, we selected research participants using stratified purposeful sampling to offer information-rich cases that could offer meaningful comparisons (Patton, 2002) of teachers who educate underrepresented racially minoritized students.

The selected participants were from various school settings: public high $(n=4)$, private high $(n=1)$, public middle $(n=1)$, private middle $(n=2)$, and charter middle schools $(n=2)$. The various school settings provided a range of insights into how districts may have responded differently under different directions from their leadership. The schools also reflected various demographics, with a predominant focus on students from underrepresented and disadvantaged backgrounds (see Table 2). The student demographics of the schools ranged as follows: 0-42\% Asian, 11-81\% Black, 16-84\% Hispanic, and 0-57\% White. The schools' student populations receiving free or reduced-priced meals ranged from 28 to $94 \%$.

Other descriptors gathered from the participants include their gender, racial identity, place of origin, age, years teaching grades 6-12, years teaching at current school, and highest education (see Table 3). Participants identified as female $(n=9)$ and male $(n=1)$, Black $(n=4)$, Hispanic $(n=1)$, White $(n=4)$, and other/multiracial

Table 1 Participants' associated schools

\begin{tabular}{ll}
\hline Type of school & Participant \\
\hline Public High School & Ayla \\
& Dahlia \\
& Melissa \\
& Kaylee \\
Private High School & Sasha \\
Public Middle School & Tameka \\
Private Middle School & Jacobi \\
Charter Middle School & Emory \\
& Evie \\
\hline
\end{tabular}

Participants' names are pseudonyms 
Table 2 Student demographic percentages of participants' schools

\begin{tabular}{lrllrll}
\hline $\begin{array}{l}\text { Participant's } \\
\text { institution }\end{array}$ & Asian & Black & Hispanic & White & Other & FRPM \\
\hline Ayla & 1 & 29 & 69 & 0 & 1 & 94 \\
Brooke & 42 & 24 & 19 & 13 & 2 & 44 \\
Dahlia & 11 & 32 & 52 & 3 & 2 & 79 \\
Emory & 2 & 11 & 84 & 1 & 2 & 92 \\
Evie & 0 & 81 & 16 & 1 & 2 & 86 \\
Jacobi & 8 & 21 & 24 & 44 & 3 & 33 \\
Kaylee & 5 & 13 & 24 & 57 & 1 & 28 \\
Melissa & 0 & 19 & 54 & 26 & 1 & 63 \\
Sasha & 10 & 40 & 50 & 0 & 0 & 88 \\
Tameka & 0 & 41 & 57 & 1 & 1 & 64 \\
\hline
\end{tabular}

Approximate percentages collected from participants. FRPM denotes free or reduced-priced meals

$(n=1)$. Most of the participants originated in the United States, were in their late 20 s or early 30s, had a master's degree, and had taught less than 10 years, with the majority of those years at their current schools.

\section{Data Sources and Analysis}

Each participant took part in phenomenological interviews, which focused on having each participant discuss their context, reconstruct their experience, and reflect on the meaning of their experience (Seidman, 2013). Given that a phenomenological approach recognizes "lived experiences" as critical to contributing to "phenomena" (Schutz, 1932/1967; Van Manen, 1990), we found it effective to engage each participant in two semi-structured interviews consisting of both scripted questions and open-ended discussion to initiate questions and follow-up probes targeting the teachers' perspectives and lived experiences (Roulston, 2010).

The first interview consisted of questions to learn more about the teachers, including their demographics and experiences teaching mathematics. As the interview continued, the teachers shared insights into their current teaching positions, with particular emphasis on their teaching responsibilities; access to support, digital resources, and professional development; and instructional practices prior to COVID-19. Developing an understanding toward the context in which the teachers taught preceding digital learning allowed both the researchers and participants time to reflect on the initial activity before it was impacted by the transition. One week later, a second interview was conducted in which the teachers were engaged in conversations about how COVID-19 had personally impacted their mathematics instruction. During this interview, the teachers reflected on changes to their teaching responsibilities; access to support, digital resources, and professional development; and the observed practical and pedagogical challenges and opportunities that resulted in the transition to digital learning. 
Table 3 Participants' demographics and experiences
Number of participants

\begin{tabular}{|c|c|}
\hline \multicolumn{2}{|l|}{ Gender } \\
\hline Female & 9 \\
\hline Male & 1 \\
\hline \multicolumn{2}{|l|}{ Racial identity } \\
\hline Black & 4 \\
\hline Hispanic & 1 \\
\hline White & 4 \\
\hline Other & 1 \\
\hline \multicolumn{2}{|l|}{ Place of origin } \\
\hline International & 2 \\
\hline United States & 8 \\
\hline \multicolumn{2}{|l|}{ Age } \\
\hline $21-24$ & 1 \\
\hline $25-28$ & 3 \\
\hline $29-33$ & 2 \\
\hline $34-37$ & 3 \\
\hline $38-41$ & 0 \\
\hline $42-45$ & 0 \\
\hline $46+$ & 1 \\
\hline \multicolumn{2}{|c|}{ Years teaching grades 6-12 } \\
\hline $1-3$ & 3 \\
\hline $4-5$ & 1 \\
\hline $6-10$ & 4 \\
\hline $11-15$ & 1 \\
\hline $16-20$ & 1 \\
\hline \multicolumn{2}{|c|}{ Years teaching at current school } \\
\hline $1-3$ & 5 \\
\hline $4-5$ & 2 \\
\hline $6-10$ & 2 \\
\hline $11-15$ & 1 \\
\hline \multicolumn{2}{|c|}{ Highest education } \\
\hline Undergraduate & 2 \\
\hline Masters & 8 \\
\hline
\end{tabular}

Both interviews were conducted over Zoom and recorded. The recordings were transcribed in order to document the conversations and interactions between the researchers and participants (Gibbs, 2007). For member-checking purposes, each participant received a copy of their transcripts for review. The participants were asked to edit, elaborate, and/or clarify their words, if necessary. Member-checking interviews were also held in order to review transcripts and confirm initial data analyses. 
Data collected from the interviews provided the research team with corroborating sources of evidence. The transcripts were coded using in vivo and descriptive coding techniques (Saldaña, 2016) and interpreted using Kvale's (1996) meaning-making methods to capture the participants' experiences. The research team then looked for patterns between the compiled codes in order to create themes that communicated perspectives and lived experiences shared by the participants. Once the themes were identified, a coding chart was created and cross-checked for coder reliability among the researchers. Throughout data analysis, the research team also performed memo writing to assist with interpreting the data (Grbich, 2013).

\section{Results}

We identified four themes that summarized urban secondary mathematics teachers' perspectives and lived experiences transitioning to digital education during the COVID-19 pandemic. In this section, we describe each theme, referencing specific events and related topics shared by the participants. By examining the themes, we highlight the observed practical and pedagogical challenges and opportunities of digital education. Particular attention is also placed on the disparities and inequities pertaining to the digital divide, including technology access and the knowledge to use such resources to support mathematics teaching and learning in the urban context.

\section{Confronting Digital Disparities and Inequities Bridging School and Home}

In speaking with the teachers, we were repeatedly told that the in-person school closures disrupted "traditional" teaching and learning routines for both the teachers and their students. Schools were described as not only structured places to learn and to challenge students' minds but also places of support for vulnerable and disadvantaged students. Many teachers indicated that their students relied on school for academic engagement and enrichment with the support of in-person relationships with teachers and peers. Schools also served as safe escapes for students who benefited from school-related services and resources (e.g., food, counseling, physical fitness). Bridging school to home did not offer the same opportunities. Thus, teachers had to rethink learning within the context of the home, which often lacked characteristics conducive to learning (e.g., quiet spaces, device access, internet capacity, parental academic supervision).

In hopes of reducing digital divide barriers, many school districts sent technology (e.g., Chromebooks, iPads, laptops) home with students and partnered with service providers to offer access to hotspots and high-speed internet. If students were not able to secure technology-related access, some teachers created packets and had their schools organize pickup or delivery options to students' homes. Although a reportedly low number of students requested packets, there was evidence that even those with technology access were not always able to use such resources to access asynchronous and synchronous materials. Several teachers noted that the main 
sources of access-related issues were linked to students having to share devices and internet simultaneously at home with other siblings and family members.

For some students, asynchronous materials were best suited for their home life given that they were able to access the material at a time of day (e.g., evenings when parents were off work) that was most beneficial for them. For other students, the structure of synchronous materials kept them focused during typical school hours. Teachers who prepared both asynchronous and synchronous learning opportunities noted that they were "working more hours at home than when at school" and, as a result, felt like they were "struggling to keep up and constantly frustrated."

Contributing to the frustration, teachers were feeling as though they were spending more time troubleshooting technology issues than providing instruction. Teachers noted that they spent many hours learning new technology that they were unfamiliar with prior to COVID-19. In the process of teaching themselves efficient ways to record videos and assess student work across various platforms, the teachers had to sacrifice their own planning time, which cut into their personal time outside of class to perform other job-related responsibilities. Teachers also had to train parents and students on how to use different technologies. Those who had prior knowledge and experience working with such resources were privileged over others who were "learning on the job." Teachers who witnessed students struggling more with the technology than the mathematical content were limited in their potential to fully contribute to their learning, which resulted in higher observed rates of student resistance and disengagement.

While many parents were supportive and appreciative of teachers' efforts to rethink learning through a remote setting, several teachers also noted concerns from parents regarding how much support would be available to their children. In some households, in-person support was limited, as some parents expressed that they did not have the skills to assist their children with some of the mathematics content they were learning. The inability to aid or strategize potential methods for solving problems often resulted in the parents feeling helpless and students feeling isolated. Additionally, some students shared with their teachers that their parents often had fixed mindsets or anxiety around the material. In turn, the students reacted similarly to learning new content. To address the anxiety surrounding learning new content in the remote setting, the teachers focused classwork mainly on prior knowledge and review, thereby strengthening students' confidence to learn new material at home. Teachers also placed a concerted effort on keeping parents abreast of the targeted objectives and tasks assigned for students by contacting parents via email and phone calls. Other lines of communication included checkpoints for students' emotional well-being and general support. As noted by the teachers, the increased communication home was welcomed by many parents and aided in building better teacher-parent relationships.

Although intentional efforts were made to offer opportunities for students to participate in learning mathematics by rethinking "classroom norms," the teachers still faced difficulties with student participation and attendance. For instance, one teacher from The Bronx, New York, shared the difficulties of not being able to control learning measures at home and how her students often lacked parental guidance due to work commitments. During the day, the lack of structured home support made it 
difficult for students to be held accountable for learning, especially when older children had to take care of younger siblings or sick family members. A Black student expressed such frustrations with the teacher reportedly saying: "Miss, I can't learn in this ghetto. I was going to school to leave this ghetto so I could learn, but COVID19 has taken me back to the ghetto and the things that I don't want to do." The student recognized school as a place to keep focused on her academics alongside peers who shared similar aspirations as well as a better place to learn than somewhere that could potentially expose her to distractions that may get her sidetracked or in trouble. The teacher went on to discuss how she could relate with her students growing up as a Black female in the city. She noted that "students must have intrinsic motivation to participate in learning, especially digital learning." For those who lack interest or are easily distracted by other factors (e.g., family stress, study environment), it can be easier to fall through the cracks when unobserved while at home learning.

\section{Modifications to Instruction and Curriculum}

Teachers also commented on how they made changes in their instructional practices that required modifications to their "traditional" practices of content delivery, student engagement, and patterns of assessment and feedback. The transition to digital education forced teachers to revise their curriculum plans and modalities for student support. As a result, some teachers shared how they felt that they were not able to cover the same mathematics content they had in face-to-face settings. For instance, one teacher said, "We had to adjust to see what was a reasonable amount of work for students to complete while they were at home. So we ended up doing about two lessons each week instead of three to four." Similarly, another teacher shared, "There was a whole unit that we cut out because we were not allowed to give more work." In contrast, another teacher commented that she covered even more content online than what she usually covered in two weeks when her students were sitting in front of her. Thus, there were varying observed modifications to curriculum, with many modifications resulting in a truncated review of the originally planned curriculum.

In addition to sharing modifications to the curriculum, the teachers also reflected on how such adaptations impacted their pedagogical strategies for providing feedback and keeping students engaged. For instance, one teacher realized she asked her students more closed-ended questions rather than open-ended questions during remote instruction, thus limiting students' conceptual understanding and connections to other mathematical topics. Another teacher who discussed how she cut out curriculum due to limited instructional time went on to talk about how she tried to maximize student engagement and practice during class meetings by creating a flipped classroom experience. She recorded her lessons prior to meeting the students and asked her students to preview the material so they could work sample problems in class together. She also commented on how she found the videos to be helpful in that students could play them as many times as needed before their class meetings. Another teacher reflected on her modifications of pedagogy, noting the following: 
In my regular instruction, I did a lot of chunk and chew or think-pair-share. And when they [the students] were working at home on these tasks, they felt more isolated, and they did not have access to actual help because some of them only imagined help as a teacher standing beside them instead of asking questions over email.

Thus, she tried to offer additional support opportunities beyond her class meetings. She shared her personal phone number for students to call or connect using FaceTime anytime they needed support. While only a few students contacted her outside of class, she noted that knowing there was an option to do so offered students a sense of "connectedness" and comfort during a time of uncertainty.

Other teachers shared reflections on how remote learning provided a window into students' cultural backgrounds, family dynamics/responsibilities, and interests that served as inspiration when generating conversation starters and tailoring lessons to students' learning needs. For example, one teacher commented on how she kept students engaged during her instruction by having them share objects in their home that were relevant to the lesson. Thus, the observed assets within the home and communities of the students served as motivation to strengthen some of the teachers' instructional practices.

Several teachers also discussed how their instruction and curriculum was impacted by limitations outside of their control. For instance, some teachers were asked by their administrators or department chairs to reduce the amount of work assigned by cutting traditional assignments in half. Other teachers were told to give no more than one hour of work each day. One teacher said, "I cut back on the quantity of what I was teaching, and so I tried to be strategic in finding topics that would not have a huge effect on students." This teacher planned on spending time during the summer to do vertical curriculum alignment with next year's teachers to ensure missing mathematics content would be made up during the next academic year. Another teacher discussed how she was hesitant to cover graphing because of the variability in access to specific graphing-related resources (e.g., calculators, software) and the knowledge to use specific applications. Additionally, many teachers were directed by their administrators to only give participation grades and not a grade for students' knowledge of the content, which often encouraged students to disengage from the lessons presented. Overall, the consensus was that curriculum modifications caused teachers to feel guilty of cheating their students out of opportunities to learn.

\section{Benefits and Challenges to Using Digital Tools}

While teachers shared various challenges to learning at home during COVID-19, there were also observed benefits to teaching with new digital tools. Not surprisingly, those opportunities were not distributed randomly. Children in certain economic situations as well as cultural eco-systems enjoyed the greatest benefits, whereas others felt frustrated or overwhelmed by feelings of being left behind. For this theme, we closely examined three conditions that gave rise to the need to consider the benefits of digital tools despite in-home disparities. 
The missing child, a term often used in the court system to describe a child in foster care, characterized many of the students who fell through the cracks during COVID-19 in mathematics education. One teacher reflected on her personal experience with a Black student named Jemimah, a pseudonym to respect confidentiality. For Jemimah, the generalities about being a missing child were true, and technology was the lynchpin. She had been in several placements and was currently in a new home and a new school with new standards and new friends. According to the teacher, she and Jemimah bonded early in the year, and Jemimah confided in her before COVID-19. Jemimah was described as bright but far behind in her studies.

When the COVID-19 pandemic response required learning at home, the teacher lost her connection to Jemimah, as the student did not have any technology or internet connection at home; instead, her foster parents dropped off and picked up packets on Friday. It was not until late April when Jemimah received a hot spot and tablet from the school that the teacher regained communication with her. Thereafter, Jemimah never missed class. She also joined the once-a-week virtual social hour and often visited the teacher's virtual office hours, not to talk about mathematics or to get help, but to talk and be part of the teacher's life. This relationship gave the teacher important insight into Jemimah's life as she navigated the COVID-19 pandemic.

After being able to connect virtually, Jemimah was engaged, worked hard, and asked questions in the online limited format. Still, there were other obstacles to learning that Jemimah had to overcome. Because she lived in a cellular dead spot, she had to go outside and sit under a park's tree where the signal was strongest to connect to class. Furthermore, some of the other foster children in her home were in elementary school, so Jemimah was tasked with helping them with their assignments. She complained about her "tutoring" responsibilities in nearly every conversation with her teacher. However, and more importantly, Jemimah seemed to be learning despite these struggles and frustrations. The teacher noticed that Jemimah seemed to be catching up with the mathematics content now that she was able to attend class virtually. She was clearly more mathematically fluent and active online once she could take control of her learning.

The teacher was grateful that the state minimum skills test had been waived due to the pandemic, because she was certain that even though Jemimah had made some amazing progress, it would not have been sufficient enough for her to achieve highly on the test that was not written to document Jemimah's progress in learning mathematics. As noted by the teacher, the test's feedback would have been another setback that might have devastating effects on the commitment both Jemimah and her teacher made to making the best out of a complex and difficult situation. The takehome message was that being a Black female in the foster care system facing grim conditions could have set Jemimah on a dismal trajectory toward abject failure. The lack of familial support, inaccessibility to technology, and general parent disinterest all intersected to potentially make this a story of failure and heartbreak. However, one teacher made the best of a challenging circumstance and was the support Jemimah needed to help her discover her own commitment to learning. Additionally, the digital support structure, once accessible, provided the framework and opportunity for Jemimah to finally feel some success with learning mathematics. 
Children with siblings were another group that struggled with the move to digital learning, as even those in the best of situations often had to share technology. Even when the internet is broadband and unlimited, parents rarely buy a computer for every individual in the household. Teachers told stories of the "technology competition" even within the households of their middle and high socioeconomic status students. Parents who were working from home often needed technology for their job-related responsibilities. As a result, their children often had to share a cell phone and/or iPad to virtually attend class. These conditions led to a great deal of difficulty in learning, especially for households with only one device, but parents were stuck in a very difficult situation, even when school districts attempted to reduce the frequency of scheduling conflicts. Some schools opted to only have classes for specific grades on specific days and times so as not to generate conflicts with technology use. Still, the policy did little for parents whose job hours were not flexible, and many students were still unable to attend classes during the amended hours. As a result of not being able to attend, record, or retain virtual class times and lessons, children were often relegated to video instruction online outside of school hours.

The competition for both bandwidth and technology was secondary to time and format. Most teachers did not have the home facilities to make and post recordings of their lessons. One teacher described how his students' parents often visited his office hours and impressed upon him how important it was to have instruction available asynchronously for the reasons previously discussed. To address the concerns, the teacher decided to create a space to record asynchronous lessons. He began by building a home office in the corner of his kitchen. He used left-over plywood from a home project, ordered chalkboard paint and chalk, and fastened it to the wall. He also used his child's teddy bear to hold his phone while recording his lessons. Then, with a little effort and the guidance of an online video, he learned to edit videos on his iPhone and post them to his Google Classroom. This teacher claimed to be a technology user but not much of an innovator, but he also acknowledged that his school provided little support or guidance for developing the skills or generating the ideas needed for improving his instruction. He also shared that he felt his administrators were more interested in making sure the teachers were spending the "right" amount of time online than they were in helping them build great online learning experiences. In the end, he became a resource for his peers and helped several other teachers at his school master the same skills he had acquired for the purpose of supporting digital learning.

Various technologies were employed by each of the teachers in this study, such as ready-made online videos, guided notes, and asynchronous independent assignments, albeit most were not sanctioned or provided by the school or district technology support personnel. The districts did, however, provide the backbone for housing online instruction. Some districts allowed different schools to adopt different platforms, but other districts adopted district-wide platforms (i.e., Google Classroom, Blackboard, Canvas, and Schoology). These platforms allowed students to share assignments and receive graded feedback. Video conferencing and chat platforms (e.g., Zoom, Google Hangouts, Skype) were used for tutorials, office hours, and class meet-ups. Some teachers also used these platforms to create social settings where they could follow-up on their regular instruction or to allow space for students 
to complete synchronous tasks and continue group activities, such as experiments, debates, projects, and student error analysis. This lent some level of normalcy to the school day. Finally, teachers included tasks from EdPuzzle, Quizlet, and Frenzy during class and follow-up sessions to engage students. Generally, teachers believed students who were able to attend synchronous lessons and group work sessions benefitted from them. Unfortunately, some students struggled to participate fully.

The teachers were univocal in their description of the challenges of digital education. They received professional development at the beginning of the transition to digital learning; however, it was mostly focused on accountability (e.g., attendance, grading), along with new expectations for parent communication and acceptability for responding to requests for parent-teacher meetings. They received limited professional development on effective ways to engage students in digital education, what technologies to use, or how to integrate them into their instruction. Most teachers voiced a need for comprehensive professional development where they could learn to create instructional videos, use video conferencing platforms, set virtual classroom norms, enact new behavior management techniques, and identify compatible digital resources to enhance remote learning. In summary, one teacher shared, "I think it's [digital education] required me to get a lot more creative because you're not there with the kids."

\section{Problematizing the Threatened Humanistic Aspect of Teaching and Learning}

Not being able to see students' faces during digital learning caused some issues with regard to the humanistic aspect of teaching and learning. In the words of one teacher, "I explain with my hands, and I need to see their faces." The teachers shared that they need to "gauge the temperature" of how the students are doing and to determine what is going on with them during lessons. It is difficult to do this without visual cues from the students. As a result, the teachers struggled to adapt to communication through Zoom, chats, or email, platforms in which it is impossible or impractical to "see" every student in real time. One teacher shared, "That's when I realized how much I relied on the non-verbal cues from my students." Furthermore, teachers and students found it difficult to remain confined to technology all day long, as it was hard to remain connected to a device that offered limited interpersonal and interactive opportunities.

Teachers expressed that their students were missing many of the social contexts of school, including afterschool clubs, sports, and extracurricular activities. One teacher shared, "They [my students] craved a social aspect" because they felt isolated when socially removed from their teachers and peers. Furthermore, students expressed that they did not feel the same level of support from their teachers because teachers were not physically present looking after them. They did not perceive that sending their questions via e-mail, taking a screenshot of their answers, and attending online tutorials constituted getting help from a teacher. Teachers responded to the dearth of social interaction by using a variety of ways to create a more communicatively rich environment by integrating Google Meet for students to catch up with one another. This strategy was met with some success. In fact, one teacher revealed 
that some students just wanted to hear or see a familiar face, so they would attend office hours just to talk with her. Despite such efforts to cultivate social interaction within the classroom community, students still expressed feelings of being disconnected. Unfortunately, many teachers felt incapable of finding alternative methods for connecting to students and helping them connect to one another, and some teachers' relationships with students were ultimately described as fractured. Still, in an odd way, some teachers felt closer to some of their students because they gained insights into students' home lives.

\section{Lessons Learned and Implications}

Education will never be the same after the COVID-19 pandemic. More than ever, it will be important for teachers to navigate the digital divide. This study offers significant contributions to mathematics education by providing a space to reflect on how urban secondary mathematics teachers can use technology to deliver equity-oriented mathematics instruction in the future.

\section{Technology Integration to Advance Mathematics Instruction}

Various technology tools can assist in advancing mathematics instruction. During uncertain times, teachers need to leverage various digital tools to support mathematics instruction and enhance student learning despite experiencing challenges and shifts in their own practices and pedagogy. This can be observed in similar works documenting how teachers have adapted technology-facilitated pedagogical innovation, among other student-centered learning efforts, to develop their professional practice (see Corkin et al., 2019; Moldavan \& Andronico, 2020). Looking forward, mathematics education must find ways to capitalize on the use of digital tools to provide additional opportunities for students to interact with mathematical concepts in various settings (e.g., asynchronous, synchronous).

Although the teachers in the study mentioned a few digital tools, more attention was placed on them creating their own videos to teach the content in lecture and flipped instruction formats. We also recommend teachers make use of a variety of commercially produced digital tools when engaged in digital learning to provide interactive opportunities for students to collaboratively engage with their peers and receive immediate feedback. While add-ons and applications (e.g., Nearpod, Pear Deck, Jamboard, Adobe Spark Video) can enhance the learning experience, other dynamic and interactive digital tools (e.g., Desmos, GeoGebra, Sketchpad, Common Online Data Analysis Platform [CODAP], Tuva, NCTM's Illuminations) can also be used to assist students in content-specific explorations, such as looking for mathematical patterns and relationships in geometry, algebra, statistics, and calculus. These digital tools can also be used alongside justice-oriented curriculum that capitalizes on students' cultural and linguistic assets to develop critical mathematics consciousness (see Butin, 2007; Dover, 2016; Kokka, 2020; Longres \& Scanlon, 2001; Valenzuela, 2016). Framing curriculum from culturally relevant, responsive, 
and justice-oriented pedagogies can assist teachers and students in developing cultural awareness and sociopolitical understandings in the context of mathematicsrelated goals reflective of students' homes and communities. With this in mind, resources (e.g., subscriptions, training) and time must be given to teachers so that they can identify which digital tools and pedagogies are effective in teaching and learning mathematics per their students' specific learning needs.

\section{Training to Support Digital Instruction}

Research-based professional development that prepares teachers for digital instruction is necessary to help teachers design effective online lessons for both face-to-face and remote learning. While interviewing teachers, it became apparent from their shared concerns that most felt abandoned by their administrators when it came to the area of meaningful professional development to assist teachers with teaching from home. Naturally, teachers described their administrators as feeling overwhelmed with institutional challenges; thus, administrators focused their attention on providing (if any) professional development opportunities that dealt with logistics rather than effective ways to deliver instruction. Teachers in this study were yearning to engage in professional development that addressed unique ways to engage students in meaningful digital learning.

When contemplating professional development opportunities, considerations must be made to assess any limitations of access to technology and the knowledge of how to use the technology by both school personnel and students/families. The teachers in this study expressed that they knew of many digital tools, but they struggled to implement or did not feel comfortable taking full advantage of the features offered by the resources. Effective professional development needs to focus on innovative ways to learn about digital tools, especially in interdisciplinary contexts (i.e., professional development with other teachers outside their disciplines). The technology teachers use must serve to simulate class activities, deepen students' understanding of mathematics, and strengthen participation from home. Teachers also need to be able to use the various tools to assess student learning progress and provide student feedback.

Even though concerns of insufficient planning, lack of training, and modified curriculum expectations served as limiting constraints, schools wishing to use digital learning need to provide appropriate support and training. Reflecting on the knowledge that teachers had to shift their perceptions about what it means to be a teacher in a digital environment (Armitage \& Nellums, 2020), schools must offer training that not only provides opportunities to study new digital tools but also reflects on what it means to teach with such resources. Schools are not alone in providing this support to teachers. Educational institutions should also assist. Some of the teachers interviewed revealed that their training for teaching in an online platform was not something that was discussed in detail during their teacher preparation programs. As such, teacher preparation should offer targeted training to equip preservice teachers with contextually nuanced opportunities to enhance instructional design and 
strengthen their content delivery. Additionally, an emphasis on addressing the inequities in the digital divide and the ways in which technology can support problematizing inequitable issues (e.g., racial identity, gender, socioeconomic status) facing urban youth (see Alvarez et al., 2020; Tichavakunda \& Tierney, 2018; Walker, 2007) should be prioritized.

\section{Open Access to Technology}

There are many facets of the education system that are deeply rooted in customs and norms. For example, teachers often receive professional development ahead of anticipated changes and have time to develop their lessons, adopt new tools, and vet textbook options. However, the magnitude of the COVID-19 pandemic allowed for none of these preparations. Targeted efforts must provide basic access to digital resources and the skills needed to use them. If these efforts are not prioritized and granted appropriate time and support for teachers to explore using the technology in the classroom, technology integration in schools will be delayed (Bauer \& Kenton, 2005). Additionally, conscious initiatives must be taken to rethink school-level barriers regarding beliefs and attitudes about teaching that uses technology (Wachira \& Keengwe, 2011).

Our analysis led us to consider the need to provide equitable access to technology and connectivity if we are to ensure quality, free education to all learners. This process can begin with initiatives to update digital infrastructure in marginalized communities, provide technology and internet subscriptions that are affordable for low-income families, and offer training to use technology for home-based education. Additionally, efforts must be made to think of ways to ensure internet access in community centers and shelters. The same must be true for providing shared equipment and training in these settings to support those who may need assistance in familiarizing themselves with new technology resources. If advances are to be made in recognizing and combating the technology-associated systemic inequities present in marginalized communities, efforts at the federal, local, and school level must be taken to seek the necessary funding, resources, and training to advance digital education.

\section{Future Research}

As discussed, there are broad implications that can be drawn from this study to provide guidance to those navigating (and disrupting) the digital divide. The participants who shared their perspectives were motivated to reflect and help others learn from their experiences. We are hopeful that the knowledge gained from this studied context of urban secondary mathematics teachers from New York City and Houston, Texas, can serve as a catalyst to other studies in analogous contexts, thereby influencing the generalizability of similar research. To see the long-term impacts of digital learning, more research is necessary. This requires ongoing support and larger discussions held with educational leaders and stakeholders at the local, state, and federal level. As these discussions unfold, our next steps should be to collect data on 
what worked well for teachers using technology and use this information to develop professional development and related support guides to ensure others can similarly benefit in the field.

\section{Conclusion}

The digital divide runs deep. To move away from a digital divide that often negatively impacts spaces of marginality and urbanicity, opportunities must be in place that prioritize digital equity, where both access and knowledge to use digital resources are available for teachers and students. With knowledge that connotations of equity can often be misconstrued with concepts of equality and sameness (Gutiérrez, 2007), attention must be redirected to the various needs of individuals through notions of fairness and inclusion. Through this lens of equity, digital equity addresses not only the physical access to material (e.g., computer hardware, software, connectivity) but also the social access of such resources that empower people to participate in cyberspaces of knowledge.

A myriad of urban issues has coalesced in this new COVID-19 era. This work provides a glimpse into the new disparities afflicting urban youth. To be specific, in cases where particular interventions to perturb the status quo with innovative instruction has been mitigated, where disruption of the pedagogy has been enacted, it is now derailed. Where pockets of success had been realized for underrepresented racially minoritized students, they are now relegated to instructional practices that once again favor majority youth living in economic standards unrealized by most urban youth. The COVID-19 pandemic has instantiated a move away from culturally relevant pedagogy and just-in-time learning and made participation in the education process strained at best for urban youth. With knowledge of a vaccine that may or may not be adequately available to urban youth, their families, and school employees, there is no guarantee that schooling will return to normal in the near future. In fact, it is possible that schooling favoring those who are best able to access digital resources and to whom this distanced variation is preferable may broaden disparities.

Navigating the digital divide barriers (e.g., lack of technology equipment, unreliable equipment, lack of technical support) makes it a struggle to implement equity-oriented technology integration. Looking forward, mathematics educators must rethink what resources are needed to bridge fluid transitions between inperson and digital instruction. Doing so will encourage educational responsibility and research that (a) advocates for student-centered and engaged remote learning, (b) problematizes the digital divide to ensure achievement gaps are not widened, (c) initiates critical conversations relevant to current reform efforts in mathematics education, and (d) opens doors for other stakeholders in the field to discuss the logistics and implications of digital education for the purposes of enhancing new ways of teaching and learning.

\section{Declarations}


Conflict of interest On behalf of all authors, the corresponding author states that there is no conflict of interest.

\section{References}

Alvarez, A., Farinde-Wu, A., Delale-O'Conner, L., \& Murray, I. E. (2020). Aspiring teachers and urban education programs. The Urban Review, 52, 880-903. https://doi.org/10.1007/ s11256-020-00550-6

Anthony, C. (1996). Active learning in a constructivist framework. Educational Studies in Mathematics, 31(4), 349-369. https://doi.org/10.1007/BF00369153

Armitage, R., \& Nellums, L. B. (2020). Considering inequities in the school closure response to COVID-19. The Lancet Global Health, 8(5), e644. https://doi.org/10.1016/S2214-109X(20) 30116-9

Association of Mathematics Teacher Educators. (2017). Standards for preparing teachers of mathematics. https://amte.net/standards

Bandura, A. (1986). Social foundations of thought and action: A social cognitive theory. Prentice-Hall.

Bauer, J., \& Kenton, J. (2005). Toward technology integration in the schools: Why it isn't happening. Journal of Technology and Teacher Education, 13(4), 519-546. https://www.learntechlib.org/prima $\mathrm{ry} / \mathrm{p} / 4728 /$.

Borba, M. C., Askar, P., Engelbrecht, J., Gadanidis, G., Llinares, S., \& Aguilar, M. S. (2016). Blended learning, e-learning and mobile learning in mathematics education. ZDM, 48(5), 589-610. https:// doi.org/10.1007/s11858-016-0798-4

Boutte, G. S. (2012). Urban schools: Challenges and possibilities for early childhood and elementary education. Urban Education, 47(2), 515-550. https://doi.org/10.1177/0042085911429583

Bray, A., \& Tangney, B. (2017). Technology usage in mathematics education research-A systematic review of recent trends. Computers \& Education, 114, 255-273. https://doi.org/10.1016/j.compedu. 2017.07.004

Buendía, E. (2011). Reconsidering the urban in urban education: Interdisciplinary conversations. The Urban Review, 43(1), 1-21. https://doi.org/10.1007/s11256-010-0152-z

Butin, D. W. (2007). Justice-learning: Service-learning as justice-oriented education. Equity \& Excellence in Education, 40(2), 177-183. https://doi.org/10.1080/10665680701246492

Canhmann, M. S., \& Remillard, J. T. (2002). What counts and how: Mathematics teaching in culturally, linguistically, and socioeconomically diverse urban settings. The Urban Review, 34(3), 179-204. https://doi.org/10.1023/A:1020619922685

Carpenter, T. P., Fennema, E., Franke, M. L., Levi, L., \& Empson, S. B. (2015). Children's mathematics: Cognitively guided instruction. Heinemann.

Chen, H., \& Peng, Z. (2020). Discontinuous learning through destructive experiences: A 'change' approach to catastrophe education in eco-pedagogy. Educational Philosophy and Theory, 52(13), 1409-1420. https://doi.org/10.1080/00131857.2020.1798756

Corkin, D. S., Coleman, S. L., \& Ekmekci, A. (2019). Navigating the challenges of student-centered mathematics teaching in an urban context. The Urban Review, 51(3), 370-403. https://doi.org/10. 1007/s11256-018-0485-6

Cradler, J., McNabb, M., Freeman, M., \& Burchett, R. (2002). How does technology influence student learning? Learning \& Leading with Technology, 29(8), 46-49.

Dolan, J. (2016). Splicing the divide: A review of research on the evolving digital divide among K-12 students. Journal of Research on Technology in Education, 48(1), 16-37. https://doi.org/10.1080/ 15391523.2015.1103147

Dover, A. G. (2016). Teaching for social justice and the Common Core: Justice-oriented curriculum for language arts and literacy. Journal of Adolescent \& Adult Literacy, 59(5), 517-527. https://doi.org/ $10.1002 /$ jaal. 488

Edyburn, D. (2013). Harness the potential of technology to support the academic success of diverse students. New Directions for Higher Education, 2011(154), 37-44. https://doi.org/10.1002/he.432

Ertmer, P. A., \& Newby, T. J. (2013). Behaviorism, cognitivism, constructivism: Comparing critical features from an instructional design perspective. Performance Improvement Quarterly, 26(2), 43-71. https://doi.org/10.1002/piq.21143 
Ferlazzo, L. (2020). What is and is not working as educators transition to online learning. Education Week. https://blogs.edweek.org/teachers/classroom_qa_with_larry_ferlazzo/2020/03/what_is_is_ not_working_as_educators_transition_to_online_learning.html.

Fulton, K., \& Sibley, R. (2003). Barriers to equity. In G. Solomon, N. Allen, \& P. Resta (Eds.), Toward digital equity: Bridging the divide in education (pp. 14-24). London: Allyn \& Bacon.

Geiger, V., Faragher, R., \& Goos, M. (2010). CAS-enabled technologies as 'agents provocateurs' in teaching and learning mathematical modelling in secondary school classrooms. Mathematics Education Research Journal, 22(2), 48-68. https://doi.org/10.1007/BF03217565

Gibbs, G. R. (2007). Analyzing qualitative data. SAGE.

Gorski, P. (2005). Education equity and the digital divide. AACE Review (formerly AACE Journal), 13(1), 3-45. https://www.learntechlib.org/primary/p/6570/

Gorski, P. C. (2009). Insisting on digital equity: Reframing the dominant discourse on multicultural education and technology. Urban Education, 44(3), 348-364. https://doi.org/10.1177/0042085908 318712

Gottschalk, F. (2019). Impact of technology use on children: Exploring literature on the brain, cognition and well-being (OECD Education Working Paper No. 195). Organisation for Economic Cooperation and Development. https://doi.org/10.1787/8296464e-en

Grbich, C. (2013). Qualitative data analysis: An introduction. SAGE.

Gutiérrez, R. (2007). Context matters: Equity, success, and the future of mathematics education. In T. Lamberg \& L. R. Wiest (Eds.), Proceedings of the 29th annual meeting of the North American chapter of the international group for the psychology of mathematics education (pp. 1-18). University of Nevada, Reno.

Howland, J. L., Jonassen, D., \& Marra, R. M. (2011). Meaningful learning with technology. Pearson Education.

Jiménez, T. C., Graf, V. L., \& Rose, E. (2007). Gaining access to general education: The promise of universal design for learning. Issues in Teacher Education, 16(2), 41-54.

Johnson, K., \& Olanoff, D. (2020). Using transformative learning theory to help preservice teachers learn mathematics that they already "know." The Mathematics Enthusiast, 17(2 \& 3), 725-769.

Kalpana, T. (2014). A constructivist perspective on teaching and learning: A conceptual framework. International Research Journal of Social Sciences, 3(1), 27-29.

Kokka, K. (2020). Social justice pedagogy for whom? Developing privileged students' critical mathematics consciousness. The Urban Review, 52(4), 778-803. https://doi.org/10.1007/s11256-020-00578-8

Kreijns, K., Kirschner, P. A., \& Jochems, W. (2003). Identifying the pitfalls for social interaction in computer-supported collaborative learning environments: A review of the research. Computers in Human Behavior, 19(3), 335-353. https://doi.org/10.1016/S0747-5632(02)00057-2

Kuhfeld, M., Soland, J., Tarasawa, B., Johnson, A., Ruzek, E., \& Liu, J. (2020). Projecting the potential impacts of COVID-19 school closures on academic achievement. Educational Researcher, 49(8), 549-565. https://doi.org/10.3102/0013189X20965918

Kvale, S. (1996). An introduction to qualitative research interviewing. SAGE.

Longres, J. F., \& Scanlon, E. (2001). Social justice and the research curriculum. Journal of Social Work Education, 37(3), 447-463. https://doi.org/10.1080/10437797.2001.10779067

Mäkinen, M. (2006). Digital empowerment as a process for enhancing citizens' participation. $e$-Learning, 3(3), 381-395. https://doi.org/10.2304/elea.2006.3.3.381

Martin, D. B., \& Larnell, G. V. (2013). Urban mathematics education. In H. R. Milner \& K. Lomotey (Eds.), Handbook of urban education (pp. 373-393). Routledge.

Matthews, L. E. (2008). Illuminating urban excellence: A movement of change within mathematics education. Journal of Urban Mathematics Education, 1(1), 1-4. https://doi.org/10.21423/jume-v1i1a20

Mezirow, J. (1991). Transformative dimensions of adult learning. Jossey-Bass.

Mezirow, J. (2012). Learning to think like an adult: Core concepts of transformation theory. In E. Taylor \& P. Cranton (Eds.), The handbook of transformative learning: Theory, research and practice (pp. 73-96). London: Jossey-Bass.

Mickle, A. D., \& Junor Clarke, P. A. (2015). Using TI-Nspire to engage preservice mathematics teachers in an exploratory geometry module. In Proceedings of the 9th meeting of the Georgia Association of Mathematics Teacher Educators (pp. 13-40). Eatonton, GA. https://doi.org/10.20429/gamte.2015. 090103

Milner, H. R., IV. (2010). Start where you are, but don't stay there: Understanding opportunity gaps, diversity and teaching in today's classrooms. Harvard Education Press. 
Milner, H. R., IV. (2012). But what is urban education? Urban Education, 47(3), 556-561. https://doi. org/10.1177/0042085912447516

Moldavan, A. M., \& Andronico, K. (2020). Using virtual coaching to assess fieldwork in mathematics teacher preparation. Connections, 30(2), 1-5. https://www.amte.net/connections/2020/11/conne ctions-thematic-articles-voices-field.

National Center for Education Statistics. (2018). Student access to digital learning resources outside of the classroom. U.S. Department of Education, Institute of Education Sciences. https://nces.ed.gov/ pubs2017/2017098/ind_11.asp

National Center for Education Statistics. (2020). Children's internet access at home. U.S. Department of Education, Institute of Education Sciences. https://nces.ed.gov/programs/coe/indicator_cch.asp

National Council of Teachers of Mathematics. (2000). Principles and standards for school mathematics. NCTM.

National Council of Teachers of Mathematics. (2014a). Access and equity in mathematics education: A position of the National Council of Teachers of Mathematics. https://www.nctm.org/uploadedFiles/ Standards_and_Positions/Position_Statements/Access_and_Equity.pdf

National Council of Teachers of Mathematics. (2014b). Principles to actions: Ensuring mathematical success for all. NCTM.

Olive, J., Makar, K., Hoyos, V., Kor, L. K., Kosheleva, O., \& Sträßer, R. (2010). Mathematical knowledge and practices resulting from access to digital technologies. In C. Hoyles \& J. B. Lagrange (Eds.), Mathematics education and technology_Rethinking the terrain: The 17th ICMI Study (pp. 133-177). Springer.

Patton, M. Q. (2002). Qualitative evaluation and research methods (3rd ed.). SAGE.

Paul, C. A. (2016). Elementary and Secondary Education Act of 1965. Social Welfare History Project. https://socialwelfare.library.vcu.edu/programs/education/elementary-and-secondary-educa tion-act-of-1965/.

Piaget, J. (1985). The equilibration of cognitive structures: The central problem of intellectual development (T. Brown \& K. L. Thampy, Trans.). University of Chicago. (Original work published 1975)

Puigjaner, R. (2016). Progressing toward digital equity. HAL Open Archives. https://hal.inria.fr/hal-01429 740 /document.

Reich, J., Buttimer, C. J., Fang, A., Hillaire, G., Hirsch, K., Larke, L., Littenberg-Tobias, J., Moussapour, R., Napier, A., Thompson, M., \& Slama, R. (2020). Remote learning guidance from state education agencies during the COVID-19 pandemic: A first look. MIT Teaching Systems Lab. https://doi.org/ $10.35542 / \mathrm{osf} .10 / 437 \mathrm{e} 2$

Renzulli, L. A. (2006). District segregation, race legislation, and black enrollment in charter schools. Social Science Quarterly, 87(3), 618-637. https://doi.org/10.1111/j.1540-6237.2006.00400.x

Robinson, L., Cotton, S. R., Ono, H., Quan-Haase, A., Mesch, G., Chen, W., Schulz, J., Hale, T. M., \& Stern, M. J. (2015). Digital inequities and why they matter. Information, Communication \& Society, 18(5), 569-582. https://doi.org/10.1080/1369118X.2015.1012532

Roessger, K. (2014). The effects of reflective activities on skill adaption in a work-related instrumental learning setting. Adult Education Quarterly, 64(4), 323-344. https://doi.org/10.1177/0741713614 539992

Roulston, K. (2010). Reflective interviewing: A guide to theory and practice. SAGE.

Saldaña, J. (2016). The coding manual for qualitative researchers. SAGE.

Schaffer, C. L., White, M., \& Brown, C. M. (2018). A tale of three cities: Defining urban schools within the context of varied geographic areas. Education and Urban Society, 50(6), 507-523. https://doi. org/10.1177/0013124517713605

Schneider, M., Teske, P., \& Marschall, M. (2000). Choosing schools: Consumer choice and the quality of American schools. Princeton University Press.

Schutz, A. (1967). The phenomenology of the social world (G. Walsh \& F. Lenhert, Trans.). Northwestern University Press. (Original work published 1932)

Seidman, I. (2013). Interviewing as qualitative research: A guide for researchers in education and the social sciences (4th ed.). Teachers College Press.

Sinclair, N., Arzarello, F., Gaisman, M. T., Lozano, M. D., Dagiene, V., Behrooz, E., \& Jackiw, N. (2010). Implementing digital technologies at a national scale. In C. Hoyles \& J. B. Lagrange (Eds.), Mathematics education and technology_Rethinking the terrain: The 17th ICMI Study (pp. 61-78). Springer.

Tate, W. (2008). Putting the "urban" in mathematics education scholarship. Journal of Urban Mathematics Education, 1(1), 5-9. https://doi.org/10.21423/jume-v1i1a19 
Teaching Excellence in Adult Literacy. (2011). TEAL Center Fact Sheet No. 11: Adult learning theories. https://lincs.ed.gov/sites/default/files/11_\%20TEAL_Adult_Learning_Theory.pdf.

Thomas, M. M., \& Hong, Y. Y. (2013). Teacher integration of technology into mathematics learning. International Journal for Technology in Mathematics Education, 20(2), 69-84.

Tichavakunda, A. A., \& Tierney, W. G. (2018). The "wrong" side of the divide: Highlighting race for equity's sake. The Journal of Negro Education, 87(2), 110-124.

Valenzuela, A. (Ed.). (2016). Growing critically conscious teachers: A social justice curriculum for educators of Latino/a youth. Teachers College Press.

Van Lancker, W., \& Parolin, Z. (2020). COVID-19, school closures, and child poverty: A social crisis in the making. The Lancet Public Health, 5(5), e243-e244. https://doi.org/10.1016/S2468-2667(20) 30084-0

Van Manen, M. (1990). Researching lived experiences: Human science for an action sensitive pedagogy. The University of Western Ontario.

Vygotsky, L. S. (1978). Mind in society. Harvard University.

Wachira, P., \& Keengwe, J. (2011). Technology integration barriers: Urban school mathematics teachers perspectives. Journal of Science Education and Technology, 20(1), 17-25. https://doi.org/10.1007/ s10956-010-9230-y

Walker, E. N. (2007). Preservice teachers' perceptions of mathematics education in urban schools. The Urban Review, 39(5), 519-540. https://doi.org/10.1007/s11256-007-0056-8

Walker, E. N. (2012). Building mathematics learning communities: Improving outcomes in urban high schools. Teachers College Press. https://doi.org/10.1007/s11256-007-0056-8

Wan, W. (2020). The coronavirus pandemic is pushing America into a mental health crisis. The Washington Post. https://www.washingtonpost.com/health/2020/05/04/mental-health-coronavirus/.

Welsh, R. O., \& Swain, W. A. (2020). (Re)Defining urban education: A conceptual review and empirical exploration of the definition of urban education. Educational Researcher, 49(2), 90-100. https://doi. org/10.3102/0013189X20902822

Yin, R. K. (2014). Case study research: Design and methods (5th ed.). London: SAGE.

Young, J. R., \& Noonoo, S. (2020). Education world reacts to coronavirus: The latest developments. EdSurge. https://www.edsurge.com/news/2020-03-05-education-world-reacts-to-coronavirus-thelatest-developments.

Publisher's Note Springer Nature remains neutral with regard to jurisdictional claims in published maps and institutional affiliations. 